\title{
One Presentation, Two Continents: Left Wrist Myositis of Distinct Etiology in Genetically Similar Individuals
}

\author{
William Murdoch, MD, and Frederick C. Rosin, MD
}

\begin{abstract}
A 34-year-old man presented with a 5-day history of rapid onset weakness of the left wrist flexor muscles, associated with fever, sore throat, arthralgias, and myalgias. A literature review to answer the question, "What could cause focal muscle weakness, fever, and myalgias?" yielded several case reports describing initial presentations of polymyositis or unusual presentations of various infectious agents. Interestingly, the man in our case had a cousin in France, with whom he had no recent contact, who presented with the same symptoms approximately 3 months earlier. Because of our patient's recent travel history, testing was performed for Lyme disease, confirming our diagnosis. The man's cousin, however, had been similarly tested and was found negative for Lyme disease. ( $\mathrm{J}$ Am Board Fam Med 2009;22:408-11.)
\end{abstract}

\section{Case History}

Mr. V is a 34-year-old man who presented to our office as a new patient. Five days previously he had developed bilateral knee and elbow joint pain, followed shortly by a low-grade fever and a sore throat. Mr. $\mathrm{V}$ visited an urgent care center 4 days before visiting our office, was diagnosed with pharyngitis, and was prescribed a 3-day course of amoxicillin ( $875 \mathrm{mg}$ twice daily). Hours after the urgent care visit but before initiating amoxicillin therapy Mr. V experienced the rapid onset of generalized myalgias and weakness in his left hand. Mr. $\mathrm{V}$ defervesced shortly after initiating amoxicillin, but his left-hand weakness became progressively worse to the point where he could not use it during his activities of daily living. He completed the amoxicillin. One day before his office visit, Mr. Vwent to an emergency department; a complete blood count, comprehensive metabolic panel, urinalysis, and crea-

This article was externally peer reviewed.

Submitted 23 December 2008; revised 30 March 2009; accepted 16 April 2009.

From the Department of Family Medicine and Public Health Sciences, Wayne State University School of Medicine, Detroit, MI.

Funding: none.

Conflict of interest: none declared.

Corresponding author: William Murdoch, MD, WSU/ Crittenton Family Medicine Residency Program, 1135 W. University Dr., Ste. \#250, Rochester Hills, MI 48307 (E-mail: bmurdoch@med.wayne.edu). tine kinase $(\mathrm{CK})$ were obtained. Pertinent positives included a CK level of 1957 and an aspartate transaminase (AST) level of 74. Mr. V was diagnosed with "myositis," given acetaminophen/hydrocodone (Vicodin, Abbott Laboratories, Abbott Park, Illinois) for pain, and was instructed to follow up. When he presented to our office, Mr. V still had left-hand weakness and significant myalgias.

During physical examination the grip strength in his left hand was rated at 3 of 5 . Mr. V otherwise had 5 of 5 motor strength in all muscle groups. A prominent solitary lymph node was noted in the right anterior cervical chain. There was no adenopathy elsewhere. The balance of the physical examination was normal; in particular no rash was present, nor was there any history of rash.

Additional laboratory studies were obtained (Table 1). In the meantime, Mr. V was empirically started on prednisone, $10 \mathrm{mg}$ daily, for a presumptive diagnosis of unspecified myositis. Results included a CK level of 2672, AST level of 119, lactate dehydrogenase level of 227, C-reactive protein level of 1.13 , and a negative hepatitis panel. Because of concern about these rising markers of muscle inflammation, the patient was asked to return to our office before our receipt of the Lyme titers. Table 1 shows laboratory value details.

During this second office visit, 7 days after the first, Mr. V reported almost complete resolution of 


\begin{tabular}{|c|c|c|c|c|}
\hline Laboratory Value & Normal Values & $\begin{array}{l}\text { Emergency Room Visit } \\
(9 / 8 / 2008)\end{array}$ & $\begin{array}{l}\text { First Office Visit } \\
(9 / 9 / 2008)\end{array}$ & $\begin{array}{l}\text { Second Office Visit } \\
(9 / 16 / 2008)\end{array}$ \\
\hline $\begin{array}{l}\text { White blood cell count } \\
\text { (thousand/cumm) }\end{array}$ & $4.5-10.5$ & 4.6 & 3.7 & 6.8 \\
\hline Lymphocyte (\%) & $13.0-43.0$ & 27.2 & 45.6 & 23 \\
\hline Aspartate aminotransferase $(\mathrm{u} / \mathrm{l})$ & $5.0-40.0$ & 74 & 119 & 34 \\
\hline Total creatine kinase $(\mathrm{u} / \mathrm{l})$ & $20-235$ & 1957 & 2672 & 156 \\
\hline C-reactive protein (mg/dL) & $<0.50$ & & 1.13 & 0.06 \\
\hline Lactate dehydrogenase $(\mathrm{u} / \mathrm{l})$ & 50 to 200 & & 227 & 170 \\
\hline $\begin{array}{l}\text { Hepatitis B virus surface } \\
\text { antigen }\end{array}$ & Negative & & Negative & \\
\hline Hepatitis $\mathrm{C}$ virus antibody & Negative & & Negative & \\
\hline Rheumatoid factor & Negative & & Negative & \\
\hline $\begin{array}{l}\text { Lyme antibody screen (Lyme } \\
\text { Index value) }\end{array}$ & $<1.00$ & & 1.24 & 1.7 \\
\hline $\begin{array}{l}\text { Lyme antibody, IgG, Western } \\
\text { Blot }\end{array}$ & Negative & & & Positive \\
\hline Parvovirus B19 IgG antibody & $<0.89$ & & & 4.12 \\
\hline Parvovirus B19 IgM antibody & Negative & & & Negative \\
\hline $\begin{array}{l}\text { Epstein-Barr virus IgG } \\
\text { antibody }\end{array}$ & $<1.20$ & & & 1.20 \\
\hline $\begin{array}{l}\text { Epstein-Barr virus IgM } \\
\text { antibody }\end{array}$ & Negative & & & Negative \\
\hline
\end{tabular}

IgG, immunoglobulin G; IgM, immunoglobulin M.

his symptoms. His grip strength had returned to normal. In addition, he stated that his myalgias had ceased a day earlier. Despite the symptomatic improvement, suspicion for Lyme disease remained high and, in the absence of titers, Mr. V was empirically placed on doxycycline, $100 \mathrm{mg}$ twice daily. Additional laboratory studies were obtained (see Table 1).

During the second visit, $\mathrm{Mr}$. V related to us that he had spoken with his mother in France (Mr. V's country of origin) and learned that one of his male cousins, with whom he had no recent physical contact, had virtually identical symptoms approximately 3 months earlier, down to involvement of the same muscle groups (left wrist flexor involvement). His mother stated, however, that the cousin's test for Lyme disease was negative. Mr. V's cousin was placed on an unknown medication and recovered completely after approximately 1 month. We recognize the second-hand nature of this information, but a more detailed discussion with our patient's cousin's physician was not possible.

Shortly after Mr. V's second office visit, his Lyme titers were returned and were positive; he was instructed to continue doxycycline for 30 days. Table 2 summarizes Mr. V's timeline.

\section{Literature Review}

We formulated a clinical question: What could cause focal muscle weakness, fevers, and myalgias? To answer this question, we searched PubMed using the keywords "muscle weakness," "fevers," and "myalgias." The results showed 15 articles, all of which were case reports and none of which featured Lyme disease. A second PubMed search using the keywords "muscle weakness" and "Lyme disease" returned 17 articles. The most relevant article was a case series of 8 patients in Germany with Lyme

Table 2. Mr. V's Timeline

\begin{tabular}{ll}
\hline Date & \multicolumn{1}{c}{ Event } \\
\hline $\begin{array}{l}\text { September 4 } \\
\text { September 5 }\end{array}$ & $\begin{array}{c}\text { Symptom onset } \\
\text { Urgent care visit; 3-day amoxicillin course } \\
\text { started }\end{array}$ \\
September 8 & Visit to emergency department \\
September 9 & $\begin{array}{c}\text { First office visit; Lyme titers \#1 drawn; } \\
\text { prednisone started }\end{array}$ \\
September 16 & $\begin{array}{c}\text { Second office visit; patient } \\
\text { symptomatically improved; Lyme titers } \\
\text { \#2 drawn; doxycycline started }\end{array}$ \\
September 17 & $\begin{array}{c}\text { Lyme titers \#1 return positive } \\
\text { September 23 }\end{array}$ \\
& Lyme titers \#2 return positive, higher \\
& Lyme Index value
\end{tabular}


disease and histologically proven myositis. Of the 8 patients, 6 were treated with antibiotics and 4 recovered. ${ }^{1}$ One recent report discussed the treatment of a patient with proven Lyme disease and progressive arm weakness with intravenous immunoglobulins after failure of antibiotic treatment. ${ }^{2}$

A common thread in these reports was dual etiologies, often a medication combined with an infection or a preexisting condition. One interesting case involved a presumed infection of unknown etiology in conjunction with simvastatin treatment that resulted in a presentation similar to Mr. V's. ${ }^{3}$ Another involved proximal muscle weakness, fever, and pain in a young man with familial Mediterranean fever, triggered by colchicine therapy (the mainstay of treatment). ${ }^{4}$ Two cases of weakness and myalgias associated with toxoplasmosis were reported: one in a patient with underlying $\operatorname{AIDS}^{5}$ and another in a previously healthy patient. ${ }^{6}$ One case series described fever, myalgias, and profound systemic illness in children in association with erlichiosis, another tick-borne disease. ${ }^{7}$

\section{Discussion}

Mr. V's case seems to be unique from anything currently reported in the medical literature. Mr. V had no significant medical history and was not on any daily medications. His family history was interesting for the identical presentation in his cousin but was otherwise unremarkable. Antibodies for erlichiosis were not drawn, which is a possible confounder given that, like Lyme disease, it is responsive to doxycycline therapy. However, erlichiosis typically presents as a much more profound illness and is not thought likely here.

The Centers for Disease Control criteria for a confirmed case of Lyme disease is "a case with at least one late manifestation that has laboratory evidence of infection." We consider our case to be confirmed, with the focal muscle weakness constituting the late manifestation and the initial Lyme Index value of 1.24, and the subsequent rise 7 days later to 1.70 , constituting the laboratory evidence of infection.

Our treatment choice of doxycycline was based on a diagnosis of Lyme disease, considering the focal muscle weakness and myalgias to be most consistent with myositis rather than neuritis or radiculopathy. There were no other neurological signs or symptoms to support a diagnosis of a neu- rological manifestation of Lyme disease. Further, the Infectious Diseases Society of America guidelines support doxycycline as a treatment choice for Lyme disease patients with neurological manifestations but without clinical signs of meningitis.

Mr. V's second blood draw, after 1 week of prednisone therapy, showed a complete normalization: CK level of 156, AST level of 34, lactate dehydrogenase level of 170 , and C-reactive protein level of 0.06 . He was contacted and instructed to taper off of his prednisone. In addition, his Lyme titers had risen ever further, confirming our diagnosis. Of further interest, titers for Epstein-Barr Virus and parvovirus B19 were drawn during Mr. V's second visit, both of which returned as positive for Immunoglobulin G but negative for Immunoglobulin $M$. This presumably indicated prior infection with or exposure to these agents. It is unknown whether these played any role in Mr. V's symptomatology. It is equally unknown whether Mr. V's cousin was tested for these entities.

$\mathrm{Mr}$. V related to us that he traveled to a city in North Carolina 3 weeks before symptom onset. He denies leaving the city and does not recall any ticks or insect bites. According to the most recent Centers for Disease Control data, ${ }^{8}$ his county of residence (in Michigan) has a higher endemicity than the city he visited in North Carolina.

The differential diagnosis of myositis is broad and includes inflammatory and infectious etiologies. Many potential causes were not tested for in this case given the quick resolution of symptoms. In cases refractory to treatment, appropriate testing would cover viruses such as coxsackie, human immunodeficiency virus, and influenza; other infectious etiologies including bacteria, fungi, and parasites (eg, toxoplasmosis); and inflammatory causes such as polymyositis or dermatomyositis.

Mr. V's cousin's identical presentation months prior could be explained by Lyme disease that simply had not seroconverted or had been adequately treated by the time his titers were drawn. It is also possible that, in the presence of Lyme disease, $\mathrm{Mr}$. V's symptoms were actually caused by an as yet unrecognized etiology, in concert with his cousin's illness. Given their recent isolation, a genetic predisposition should be considered; however, our literature search did not reveal any known diseases with strong hereditary patterns that could explain these symptoms. 


\section{Conclusion}

We presented a case of a 34-year-old man with an unusual presentation of Lyme disease, synchronous with an identical presentation in a geographically isolated cousin. This case emphasizes the importance of thorough history taking, particularly family and travel histories. In addition, we emphasize the variety of presentations of Lyme disease, a relatively common disorder, that often will not include a rash and may include focal muscle findings. The authors recommend further surveillance for this constellation of symptoms, diagnosis, and family, and propose genetic investigation if similar cases are found.

\section{References}

1. Reimers CD, de Koning J, Neubert U, et al. Borrelia burgdorferi myositis: report of eight patients. J Neurol 1993;240:278-83.

2. Rupprecht TA, Elstner M, Weil S, Pfister HW.
Autoimmune-mediated polyneuropathy triggered by borrelial infection? Muscle Nerve 2008;37:781-5.

3. Finsterer J, Zuntner G. Rhabdomyolysis from Simvastatin triggered by infection and muscle exertion. South Med J 2005;98:827-9.

4. Sayarlioglu M, Sayarlioglu H, Ozen S, Erkoc R, Gul A. Colchicine-induced myopathy in a teenager with familial Mediterranean fever. Ann Pharmacother 2003;37:1821-4.

5. Gherardi R, Baudrimont M, Lionnet F, et al. Skeletal muscle toxoplasmosis in patients with acquired immunodeficiency syndrome: a clinical and pathological study. Ann Neurol 1992;32:535-42.

6. Adams EM, Hafez GR, Carnes M, Wiesner JK, Graziano FM. The development of polymyositis in a patient with toxoplasmosis: clinical and pathologic findings and review of literature. Clin Exp Rheumatol 1984;2:205-8.

7. Schutze GE, Jacobs RF. Human monocytic ehrlichiosis in children. Pediatrics 1997;100:E10.

8. Centers for Disease Control. National Lyme disease risk map. Last reviewed April 28, 2004 Available at: http://www.cdc.gov/ncidod/dvbid/lyme/riskmap.htm. Accessed May 13, 2009. 